Article

\title{
Rapid Detection of Thermal Treatment of Honey by Chemometrics-Assisted FTIR Spectroscopy
}

\author{
Olga Antonova ${ }^{1, *}$, Javier Calvo ${ }^{2}$ and Andreas Seifert ${ }^{1,3} \mathbb{D}$ \\ 1 CIC nanoGUNE BRTA, 20018 San Sebastián, Spain; a.seifert@nanogune.eu \\ 2 CIC biomaGUNE, Basque Research and Technology Alliance (BRTA), 20014 San Sebastián, Spain; \\ jcalvo@cicbiomagune.es \\ 3 IKERBASQUE, Basque Foundation for Science, 48013 Bilbao, Spain \\ * Correspondence: antonovaov1987@ya.ru; Tel.: +34-64-442-8382
}

check for

updates

Citation: Antonova, O.; Calvo, J. Seifert, A. Rapid Detection of Thermal Treatment of Honey by Chemometrics-Assisted FTIR Spectroscopy. Foods 2021, 10, 2892. https://doi.org/10.3390/ foods10112892

Received: 26 October 2021 Accepted: 19 November 2021 Published: 22 November 2021

Publisher's Note: MDPI stays neutral with regard to jurisdictional claims in published maps and institutional affiliations.

Copyright: (c) 2021 by the authors. Licensee MDPI, Basel, Switzerland. This article is an open access article distributed under the terms and conditions of the Creative Commons Attribution (CC BY) license (https:// creativecommons.org/licenses/by/ $4.0 /)$.

\begin{abstract}
Honey, as a nutritious natural sweetener produced by honeybees, offers a unique biochemical composition with great benefit to human health. Transportation and storage conditions as well as violations of processing can lead to decomposition of vitamins, destruction of the integrity of the antioxidant components and enzymes, and further biochemical changes with impact on nutritional quality. We developed a fast detection method of adulterations or changes of honey caused by thermal exposure, which does not require any sample pretreatment. By Fourier-transform infrared spectroscopy, supported by chemometrics methods, we investigated three types of raw honey before and after heat treatment for varying exposure times at different temperatures. Applying principal component analysis and linear discriminant analysis to the preprocessed spectroscopic data, allowed us to discriminate raw honey from thermally altered ones even at low temperatures of $40{ }^{\circ} \mathrm{C}$ with high accuracies $\geq 90 \%$.
\end{abstract}

Keywords: FTIR; honey quality; PLS; LDA; temperature treatment

\section{Introduction}

Honey is a natural biological high-value product, produced by honeybees from the nectar of blossoms, and collected and combined with specific substances of their own. The main components of honey are sugars-fructose, glucose, maltose, sucrose. Moreover, it contains acids, proteins, minerals, vitamins, phenols, enzymes and other substances, in total more than 400 different substances [1]. There are many different reports of the use of honey from ancient times, not only as food but for medical purposes, and it has found its place in modern medicine too [2-4].

Raw honey, which comes "straight from the beehive" without any treatment, contains bee pollen, propolis, and beeswax, which have antibacterial activity and may function as antioxidants, but also some undesirable materials, such as yeast, that are to be removed for better product quality and shelf-life [5,6]. Even though improper processing can be detrimental to the quality of honey and its biological and bioactive chemical properties, there is no guideline for honey treatment based on types and origin.

Commercial processing of honey is usually accompanied by filtering and heating in order to purify, filter, facilitate packaging, to inhibit microorganism growth, reduce moisture content to standard level, and to delay the crystallization process $[7,8]$. In earlier studies, Fourier-transform infrared (FTIR) spectroscopy was used with chemometrics to categorize honey and detect hydroxymethylfurfural (HMF) level and diastase activity [9-11]. Raw honey, containing more than $20 \%$ moisture, is easy to ferment, independent of the initial yeast count that affects the honey quality and shelf life [12]. The two most sensitive parameters regarding heating process are HMF content and diastase activity. HMF is an organic compound formed by the dehydration of certain sugars and various processed foods in acidic environments when they are heated through the Maillard reaction [13]. 
HMF content shows high values in honey that has undergone heat treatment, stored in non-adequate conditions, or adulterated with invert syrup [14]. Based on the European Honey Directive, HMF content is used for quality control of honey and should not exceed $40 \mathrm{mg} / \mathrm{kg}$, excluding honey of declared origin from regions with tropical climate and blends of these honeys, for which the limit is $80 \mathrm{mg} / \mathrm{kg}$ (Council Directive 2001/110/EC).

To reduce the water content in honey below $20 \%$ and eliminate yeast destruction for shelf-life prolongation, a wide range of heating temperatures-ranging from 30 to $140{ }^{\circ} \mathrm{C}$ is applied by honey producers worldwide, with treatment time ranging from a few seconds up to several days. It was investigated that heating up to $80{ }^{\circ} \mathrm{C}$, between 60 and $30 \mathrm{~s}$ destroys all microorganisms responsible for quality damage without spoiling the honey [15]. This treatment was considered a mild or more suitable treatment condition. Results of the investigation of honey from Crete [16] showed a significant alteration of quality parameters under heating at $65^{\circ} \mathrm{C}$ for $6 \mathrm{~h}$. Pine honey was the most resistant sample to HMF formation in all heating procedures, and multifloral honey was the least altered in its enzymatic activity through the whole thermal process. As a result, optimal heating conditions strongly rely on geographical and botanical origin of honey, however, in general, heat processing should be reduced where possible to maintain health-promoting effects.

To preserve nutrients in honey as long as possible, its moisture content should be less than $17.1 \%$ and storage temperature below $11^{\circ} \mathrm{C}$ [8]. However, it is not always possible to follow treatment and storage requirements due to weather conditions during the extraction of honey or during transportation. As quality of honey in terms of bioactivity is important, it is the end-user's right to receive controlled or certified honey that proves absence of falsification or improper storage.

Taking such requirements and boundary conditions into consideration, the aim of this study was to develop a protocol for rapid detection of possible heat treatment of raw honey, subject to transportation, storage, or even adulteration. The developed method is based on chemometrics-supported spectroscopy. Using FTIR spectroscopy, we investigated the spectra of three types of honey, both raw and thermally treated, with varying time intervals and temperatures for the treatment. As chemometric methods, we employed PCA (principal component analysis) and LDA (linear discriminant analysis) for discrimination and multinomial classification and confirmed our results by chromatography as reference method.

\section{Materials and Methods}

Commercially available raw honeys from eucalyptus, acacia, and orange blossom were analyzed in this study (Bona Miel organic, Alicante, Spain). According to the declaration of the manufacturers on the labels, honey was harvested both in the European Community (EC) and non-EC countries. Raw honey samples were supplied directly as they had been obtained from beekeepers and had not undergone any heating or filtration. Before the analysis, the samples were stored in a dark place at room temperature. From each honey type, we took three samples and performed three measurements each; corresponding results are given in Table 1 . The moisture of honey was detected by refractometry, using the Handheld Digital Refractometer PCE-DRH 1 Honey (PCE Instruments UK Ltd., Southampton, United-Kingdom). Pre-treatment was done in a water bath at $40{ }^{\circ} \mathrm{C}$ until visible dissolution of any crystallization. The moisture content of honey samples was measured at $20^{\circ} \mathrm{C}$.

$\mathrm{pH}$ was determined according to the method described in the "Techniques for the Evaluation of Physicochemical Quality and Bioactive Compounds in Honey" [17]. Ten grams of honey were dissolved in $75 \mathrm{~mL}$ of distilled water; thereafter a direct reading was taken for each honey sample from a pH meter (VWR pH100, YSI Inc., Yellow Springs, OH, USA) calibrated with appropriate buffers of $\mathrm{pH} 4.0$ and 7.0. 
Table 1. Physicochemical parameters including standard deviation (SD) of different raw honey types. Data are based on three samples per honey type and three measurements each.

\begin{tabular}{|c|c|c|c|c|c|c|}
\hline Honey Type & $\begin{array}{c}\text { Moisture } \\
(\%)\end{array}$ & $\begin{array}{c}\text { Fructose } \\
(\%)\end{array}$ & $\begin{array}{c}\text { Glucose } \\
(\%)\end{array}$ & $\begin{array}{c}\text { Sucrose } \\
(\%)\end{array}$ & $\mathrm{pH}$ & $\begin{array}{c}\text { HMF } \\
(\mathrm{mg} / \mathrm{kg})\end{array}$ \\
\hline Eucalyptus & $18.21 \pm 0.16$ & $38.5 \pm 1.2$ & $21.33 \pm 0.66$ & $0.136 \pm 0.012$ & $3.81 \pm 0.12$ & $26.51 \pm 0.87$ \\
\hline Acacia & $17.54 \pm 0.13$ & $32.45 \pm 0.14$ & $20.9 \pm 3.0$ & $0.3251 \pm 0.0031$ & $4.15 \pm 0.14$ & $9.43 \pm 0.53$ \\
\hline Orange blossom & $17.53 \pm 0.12$ & $34.36 \pm 0.19$ & $24.71 \pm 0.62$ & $4.078 \pm 0.018$ & $3.89 \pm 0.11$ & $16.10 \pm 0.64$ \\
\hline
\end{tabular}

HMF: hydroxymethylfurfural.

Sugar content was determined by GC-FID (gas chromatography, flame ionization detector; Agilent, Santa Clara, CA, USA) following the described Pierce-Portallier method [18]. For the GC-FID analysis, Openlab CDS Chemstation software was used (Agilent, Santa Clara, CA, USA). Briefly, calibration standard (glucose, fructose, and sucrose) and honey samples $(50 \mathrm{mg} / \mathrm{mL})$ were prepared in miliQ water containing $10 \mathrm{mg} / \mathrm{mL}$ of fucose as internal standard. Then, $30 \mu \mathrm{L}$ of samples were dried at $50{ }^{\circ} \mathrm{C}$ overnight and $200 \mu \mathrm{L}$ oxime reagent was added to dried samples, mixed and heated at $70{ }^{\circ} \mathrm{C}$ for $30 \mathrm{~min}$. Next, samples were cooled to room temperature and $100 \mu \mathrm{L}$ of hexamethyldisilazane and $10 \mu \mathrm{L}$ of TFA (trifluoroacetic acid) were added and mixed for $30 \mathrm{~s}$. Samples were centrifuged for $30 \mathrm{~s}$ and the supernatants were placed on GC vials. The quantification of sugars was performed by an 8890 Agilent GC-FID system (Agilent, Santa Clara, CA, USA). The separation was carried out using an Agilent HP 5 column ( $30 \mathrm{~m}, 0.32 \mathrm{~mm}, 0.25 \mu \mathrm{m}$ ) (Agilent, Santa Clara, CA, USA), the injection volume was $1 \mu \mathrm{L}$ and the injector temperature was set to $280{ }^{\circ} \mathrm{C}$. The oven temperature was initially set to $100{ }^{\circ} \mathrm{C}$ and was increased for $17 \mathrm{~min}$ at $10^{\circ} \mathrm{C} / \mathrm{min}$ until $270{ }^{\circ} \mathrm{C}$. Finally, the temperature was held at $20^{\circ} \mathrm{C}$ for $5 \mathrm{~min}$. Total run time was $22 \mathrm{~min}$.

HMF was quantified by an ACQUITY UHPLC (ultra-high-performance liquid chromatography) system equipped with a photodiode-array detector (Waters, Mildford, MA, USA). For the UHPLC data acquisition and analysis, Masslynx software v4.1 was used (Waters, Milford, MA, USA). Honey samples (50 mg/mL of honey in milliQ water) and HMF calibration standards were prepared immediately before their analysis. The separation of HMF was performed using an Acquity BEH C18 reverse phase column $(50 \times 2.1 \mathrm{~mm}$, $1.7 \mu \mathrm{m})$ (Waters, Mildford, MA, USA) at $30{ }^{\circ} \mathrm{C}$. The elution buffers were $0.1 \%$ formic acid in water (A) and acetonitrile (B), and the chromatographic method was run under the following gradient conditions: 99\% A over $1 \mathrm{~min}, 99-1 \%$ over 1 to $6 \mathrm{~min}, 1 \%$ for $2 \mathrm{~min}$, $1-99 \%$ for $0.5 \mathrm{~min}$ and $99 \%$ A for $1.5 \mathrm{~min}$ before the next injection. The column temperature was set at $30{ }^{\circ} \mathrm{C}$, the injection volume was $5 \mu \mathrm{L}$, and the flow rate was kept constant at $300 \mu \mathrm{L} / \mathrm{min}$. The detection and quantification of HMF was obtained after monitoring the UV signal at $284 \mathrm{~nm}$ wavelength.

FTIR measurements for honey did not require any sample preparation; a single droplet was put onto the ATR crystal. FTIR spectra were taken with the Frontier MIR (midinfrared) Spectrometer (Perkin Elmer, Waltham, MA, USA), applying the attenuated total reflectance (ATR) technique. Spectra were recorded with 48 scans per spectrum from 4000 to $600 \mathrm{~cm}^{-1}$. PerkinElmer software (Perkin Elmer, Waltham, MA, USA) was used for the FTIR data acquisition. To minimize the influence of temporal baseline shifts, a background spectrum against air was recorded before each sample spectrum. In order to prevent influence from measurement artifacts on a longer timescale, the spectra were measured in randomized order. To improve the signal-to-noise ratio, a total number of 50 spectra from each sample was acquired and averaged for further analysis; technically, only one drop of honey was required for each spectrum to cover the ATR crystal. For the combined method used, consisting of the FTIR spectroscopy unit, data preprocessing, and machine learning algorithms PCA and LDA, and with its inherent resolution and uncertainties, we observed a kind of threshold characteristic for the discrimination of time-dependent heating. At $40{ }^{\circ} \mathrm{C}$ thermal treatment, only after around $3.5 \mathrm{~h}$ a clear discrimination from 
raw honey could be identified, and for the case of $70{ }^{\circ} \mathrm{C}$, the observed threshold for clear discrimination starts after $15 \mathrm{~min}$.

Temperature and time of thermal treatment were based on common heating practices by beekeepers and manufacturers during honey processing and average time of the delivery process [19]. Moreover, honey heat-treatment at temperature lower than $75{ }^{\circ} \mathrm{C}$ does not lead to fast HMF formation [20]. Equal volumes of each honey were placed in $5 \mathrm{~mL}$ Eppendorf vials; thermal treatment was carried out in the Thermomixer Comfort (Eppendorf AG, Hamburg, Germany) at $40{ }^{\circ} \mathrm{C}$ for $3.5,5.5,7.5$, and $24 \mathrm{~h}$ and at $70{ }^{\circ} \mathrm{C}$ for $15,30,60,90$, and $120 \mathrm{~min}$; honey was cooled down to room temperature in a dark place for $4 \mathrm{~h}$ before further analysis. Because of slow mutual transformation processes between sugars that influence the clear separation of honey that underwent thermal treatment, we present in the main body of the paper data with the extreme values of thermal treatment, at $70{ }^{\circ} \mathrm{C}$ for 15 and $120 \mathrm{~min}$ and at $40{ }^{\circ} \mathrm{C}$ for 3.5 and $24 \mathrm{~h}$. Accordingly, the results give a clearer picture of our findings. The complete data with all heating periods is shown in the Supplementary Materials in Figures S1 and S2.

Before analyzing the measured spectra by chemometric methods, and to guarantee sample heterogeneity for obtaining reliable results, the data were preprocessed by the following steps. Due to changes in the dynamics of the spectra, best results were obtained using min-max normalization (numpy 1.18.1 "min" and "max" functions) for all FTIR spectra and then smoothed using a Savitzky-Golay filter with $5 \mathrm{~cm}^{-1}$ window width and third-order polynomials. PCA and LDA were realized for raw and heated honey samples using the Python-based libraries Numpy [21] and Scikit-learn [22]. PCA is a statistical method for reducing the dimensionality of datasets, but at the same time minimizing information losses [23]. LDA models the differences in the data, in a way that the differences in intraclass variations is maximized. Calibration and validation models were developed to predict heating treatment on the basis of the spectral information mainly in the region of $800-1500 \mathrm{~cm}^{-1}$. This spectral region contains all necessary characteristic bands related with sugar transformations. Any other spectral regions introduce more noise into the data and downgrade the results. For cross-validation of our data, we used one of the common techniques, the train-test-split approach, which randomly splits the complete data into a training set of $75 \%$ and a test set of $25 \%$ of the data; then we applied LDA.

\section{Results and Discussion}

FTIR spectra of both raw and thermally treated honey show various narrow vibrational bands in the spectral range from $600-4000 \mathrm{~cm}^{-1}$, as shown in Figure 1a. Characteristic bands in the FTIR spectra of honey related to the content of carboxylic acids, alcohols, carbon, and aromatic $\mathrm{C}-\mathrm{H}$ groups are presented in Table 2, based on prior assignments by Kedzierska-Matysek et al. [24] and Kasprzyk et al. [25].

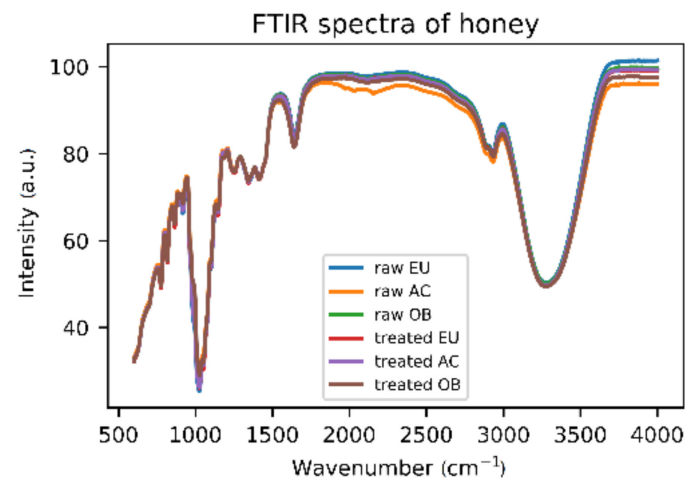

(a)

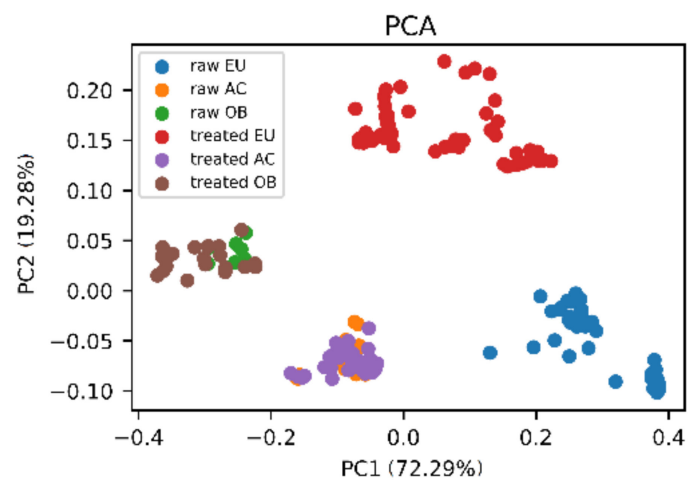

(b)

Figure 1. Raw and thermally treated honey samples-120 min at $70{ }^{\circ} \mathrm{C}$. (a) FTIR spectra. (b) Principal component score plot based on PCA (principal component analysis) applied to the spectral range of $600-4000 \mathrm{~cm}^{-1}$ from FTIR data. EU: eucalyptus, AC: acacia, OB: orange blossom. 
Table 2. Assignment of absorption peaks of the FTIR spectra from honey.

\begin{tabular}{|c|c|}
\hline $\begin{array}{l}\text { FTIR Wavenumber } \\
\qquad\left(\mathrm{cm}^{-1}\right)\end{array}$ & Type and Origin of Vibration \\
\hline 3281 & $v(\mathrm{O}-\mathrm{H})$ in $\mathrm{H}_{2} \mathrm{O}$ \\
\hline 2933,2890 & $\begin{array}{c}v(\mathrm{C}-\mathrm{H}) \text { or / and } v\left(\mathrm{NH}_{3}\right) \text { of free } \\
\text { amino acids }\end{array}$ \\
\hline 1639 & $\sigma(\mathrm{OH})$ from $\mathrm{H}_{2} \mathrm{O}$ \\
\hline 1456, shoulder & $\delta(\mathrm{O}-\mathrm{CH})$ and $\delta(\mathrm{C}-\mathrm{C}-\mathrm{H})$ \\
\hline 1415 & $\begin{array}{l}\delta(\mathrm{O}-\mathrm{H}) \text { in } \mathrm{C}-\mathrm{OH} \text { group } \\
+\delta(\mathrm{C}-\mathrm{H}) \text { in alkenes }\end{array}$ \\
\hline 1342 & $\delta(\mathrm{OH})$ in $\mathrm{C}-\mathrm{OH}$ group \\
\hline $1249,1189,1148$ & $\begin{array}{c}v(\mathrm{C}-\mathrm{H}) \text { in carbohydrates or / and } \\
v(\mathrm{C}-\mathrm{O}) \text { in carbohydrates }\end{array}$ \\
\hline 1100 & $v(\mathrm{C}-\mathrm{O})$ in $\mathrm{C}-\mathrm{O}-\mathrm{C}$ group \\
\hline $1051,1023,981,965$ & $\begin{array}{c}v(\mathrm{C}-\mathrm{O}) \text { in } \mathrm{C}-\mathrm{OH} \text { group or } \\
v(\mathrm{C}-\mathrm{C}) \text { in the carbohydrate structure }\end{array}$ \\
\hline 919 & $\delta(\mathrm{C}-\mathrm{H})$ \\
\hline $894,865,817$ & anomeric region of carbohydrates or $\delta(\mathrm{C}-\mathrm{H})$ \\
\hline
\end{tabular}

v-stretching vibrations, $\delta$-deformation vibrations.

By visual inspection, it is difficult, or rather impossible, to identify the FTIR signals responsible for the changes during heat treatment because of the complex spectra and very minor changes. To unveil hidden information from the spectra, different kinds of chemometrics analysis were used to process the spectral data and to determine the difference between raw and heated honey.

Spectral data span a high-dimensional space and cannot be used for classification via discriminant analysis without preprocessing. PCA, as one of the most used multivariate analysis techniques, was employed to transform the data set into a reduced new set of variables. We found that a full spectral range without preselection did not lead to an acceptable result. Few works have reported on feature extraction from FTIR spectra, such as the definite wavelength range or using derivatives [26]. In our case, using the spectral region $800-1500 \mathrm{~cm}^{-1}$ with the main characteristic bands, spectra have been classified correctly with high accuracy.

The variability of the PCA result for the dataset projected onto the first two principal components (PCs) is shown in Figure 1b. PCA is not a quantitative classifier, however, it constitutes a useful tool for the first visual inspection. Moreover, PCA is the most promising tool to detect the adulteration of honey with respect to different adulterant sugars: glucose, fructose, sucrose, etc. $[11,27]$. From the figure it is evident that the composition of each honey is very different, moreover, the composition of eucalyptus honey changes a lot during the heating. For a more detailed analysis, each honey was investigated separately.

Eucalyptus honey was heated at $70^{\circ} \mathrm{C}$ for $15,30,60,90$, and $120 \mathrm{~min}$. The maximum changes during heating occurred in the range of $940-1100 \mathrm{~cm}^{-1}$. As shown in Figure 2, temperature increasing leads to gradual changes in the ratio between different bands. It is obvious from FTIR spectra that honey heating leads to a change in the ratio of the intensities of the bands at $990 \mathrm{~cm}^{-1}$ and $1050 \mathrm{~cm}^{-1}$, corresponding to fructose and glucose respectively [28]. These changes could be attributed either to Maillard reaction or sugar intermutations. Since Maillard reaction is $\mathrm{pH}$-dependent (due to $\mathrm{pH}$-dependent protonation of amino acids), different honeys have different reaction rates, and as a consequence, will require individual optimization of the model for exact honey type and species. 


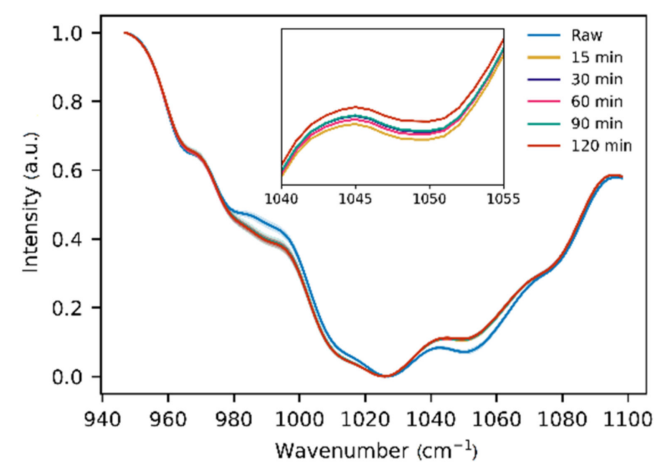

Figure 2. Fingerprint region of FTIR spectra of eucalyptus honey before and after thermal treatment at $70{ }^{\circ} \mathrm{C}$ for $15,30,60,90$, and $120 \mathrm{~min}$.

Figure 3 shows how PCA, applied to FTIR spectra, can separate raw and treated eucalyptus honey. Even though thermal treatment for 15 and $120 \mathrm{~min}$ at $70^{\circ} \mathrm{C}$ cannot be separated completely by PCA, we can see a clear differentiation. Based on loadings of PCs, the major distinctive features between raw and heated honey are located at $\sim 990 \mathrm{~cm}^{-1}$ and $1050 \mathrm{~cm}^{-1}$, which coincides with the results obtained from spectra before.

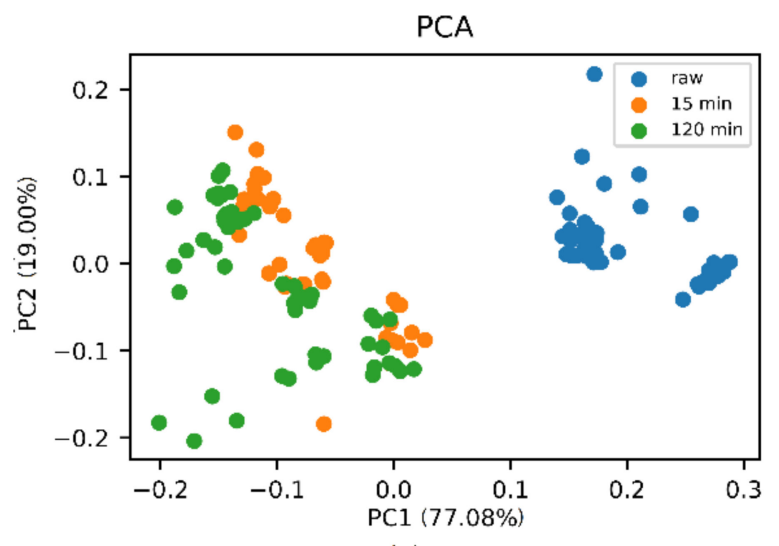

(a)

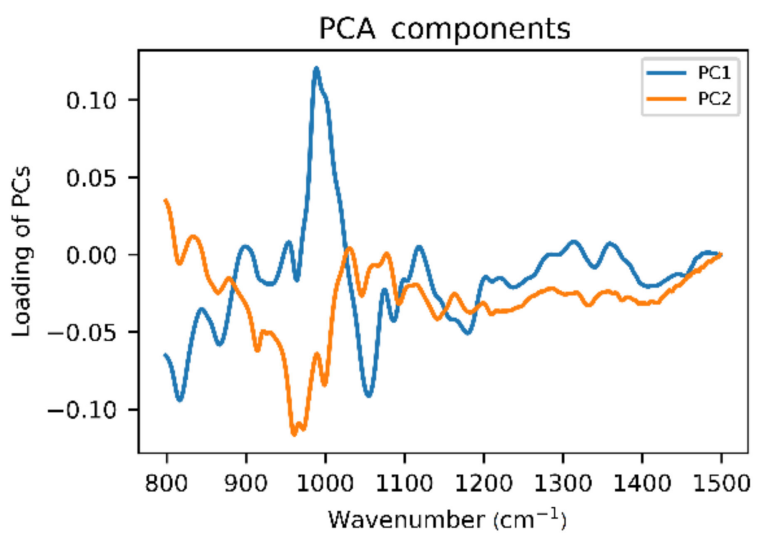

(b)

Figure 3. (a) Principal component score plot and (b) loading plot of PCs of raw and thermally treated eucalyptus honey samples-15 and $120 \mathrm{~min}$ at $70{ }^{\circ} \mathrm{C}$-based on PCA applied to the spectral range of $800-1500 \mathrm{~cm}^{-1}$ from FTIR data.

To further validate, better classify, and finally quantify the three different classes of samples, we applied LDA as a classifier. Figure 4 demonstrates that the developed classification model, based on a training set of 38 samples, is nicely verified by the test set, consisting of 12 samples for raw honey. In comparison with the PCA score plot, LDA is able to clearly distinguish between the honey samples that had been treated for 15 and 120 min at $70^{\circ} \mathrm{C}$, with test sets of 11 and 12 samples, respectively.

As a validation method, a confusion matrix was calculated, whose corresponding results are listed in Table 3. As major figures of merit, accuracy, precision, recall, and F1 score have been calculated. Overall accuracy represents an average performance of multiclass results, whereas precision, recall, and F1 score correspond to the performance of each class.

Out of 38 honey samples in these three different groups, 36 samples were correctly classified, yielding an overall accuracy of the model of 0.947 .

In a second experiment, the thermal treatment was done at $40^{\circ} \mathrm{C}$ at different heating times according to the explanations in the Section 2. Again, PCA delivers a well-clustered visual discrimination in a two-dimensional visualization of raw honey from honey after thermal treatment. However, as before, the two differently treated honey samples cannot 
entirely be separated (see Figure S3). As in the previous case, the dominant spectral feature for differentiation is located at $987 \mathrm{~cm}^{-1}$.

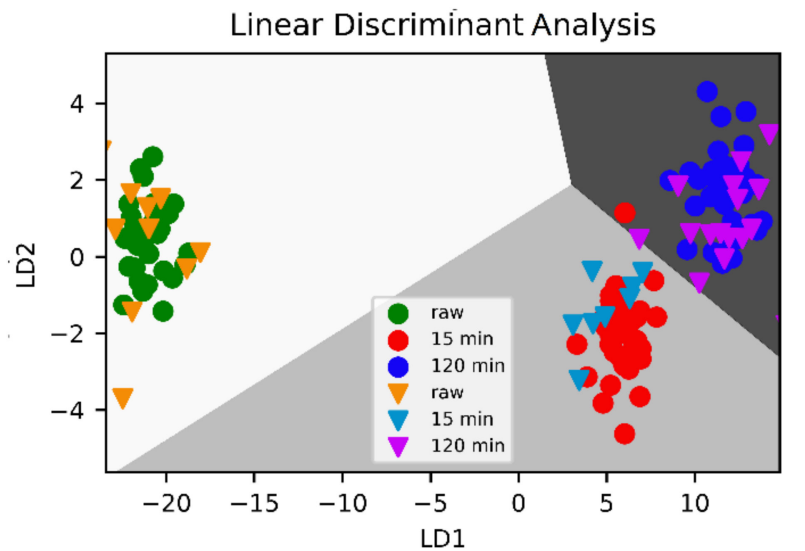

(a)

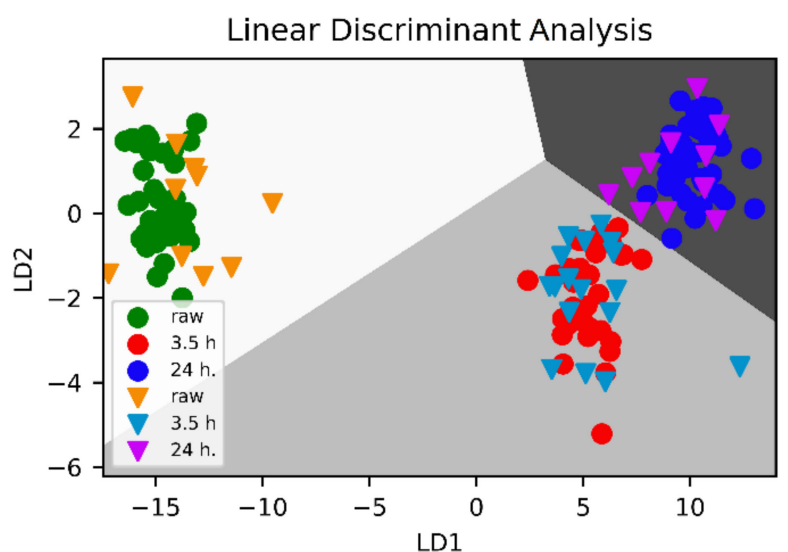

(b)

Figure 4. Discrimination of eucalyptus honey obtained by LDA of FTIR spectra based on analysis of the spectral range of $800-1500 \mathrm{~cm}^{-1}$. (a) Samples heated at $70{ }^{\circ} \mathrm{C}$. Achieved overall accuracy is 0.947 . (b) Samples heated at $40{ }^{\circ} \mathrm{C}$. Achieved overall accuracy is 0.895 . Dots: training set, triangles: test set. LD - linear discriminant.

Table 3. Precision, recall, F1 score, and overall accuracy for raw and heated eucalyptus honey at $70{ }^{\circ} \mathrm{C}$ for different heating times.

\begin{tabular}{ccccc}
\hline Group & Precision & Recall & F1 Score & Overall Accuracy \\
\hline Raw & 1.000 & 1.000 & 1.000 & \\
Heated 15 min & 1.000 & 0.818 & 0.900 & 0.947 \\
Heated 120 min & 0.875 & 1.000 & 0.933 & \\
\hline
\end{tabular}

Again, we applied LDA for classification, with the corresponding graphical illustration in Figure $4 \mathrm{~b}$. A decrease of heating temperature led to a decrease of the overall classification accuracy; however, raw honey was still clearly differentiated from thermally treated honey with an accuracy of $100 \%$. The outcome of the confusion matrix is listed in Table 4.

Table 4. Precision, recall, F1 score, and overall accuracy for raw and heated eucalyptus honey at $40{ }^{\circ} \mathrm{C}$ for different heating periods.

\begin{tabular}{ccccc}
\hline Group & Precision & Recall & F1 Score & Overall Accuracy \\
\hline Raw & 1000 & 1.000 & 1.000 & \\
Heated 3.5 h & 0.765 & 1.000 & 0.867 & 0.895 \\
Heated 24 h & 1.000 & 0.667 & 0.800 & \\
\hline
\end{tabular}

One of the most sensitive parameters regarding heating process or storage in nonadequate conditions is the HMF content. However, based on literature research, FTIR is not sensitive enough for detecting changes less than $13 \mathrm{mg} / \mathrm{kg}$ [26]. Additionally, Tosi et al. observed that HMF content didn't exceed the $40 \mathrm{mg} / \mathrm{kg}$ acceptance limit even for heating at $140{ }^{\circ} \mathrm{C}$ for $60 \mathrm{~min}$ [15]. Thereby changes in HMF during thermal treatment do not deliver significant input that is sensitive enough for FTIR spectroscopy, which was confirmed by UHPLC/UV measurements (Table S1).

Another parameter sensitive to heating is the carbohydrate content. A characteristic feature of honey is its composition. That depends on floral source, geographical origin, seasonal, and environmental factors. Accordingly, this greatly complicates the quality control of honey. To confirm that our PCA/LDA model, mostly based on glucose and fructose concentration, works correctly, the relative changes of fructose and glucose concentration 
during the heating were calculated based on the data of chromatography, taking total concentration of sugars as $100 \%$ (Table S2). Figure 5 confirms, that the higher the changes in sugar concentrations are due to heating, the more accurately the model works. These changes are related to the composition of the honey and its $\mathrm{pH}$. Additionally, Figure S4 shows that the major changes during heating occur in the first few minutes of heating, independent of temperature.

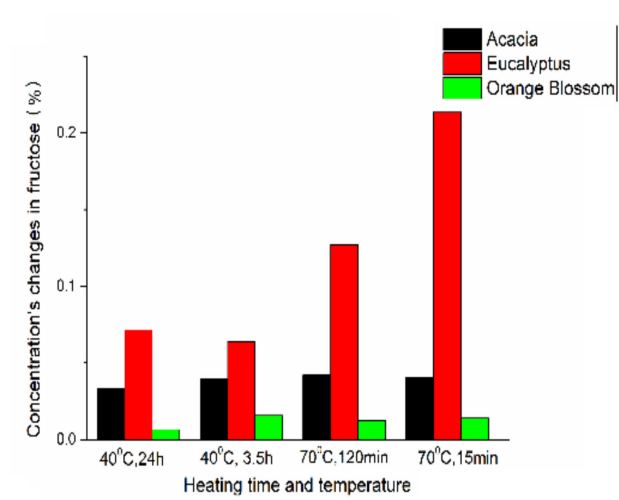

(a)

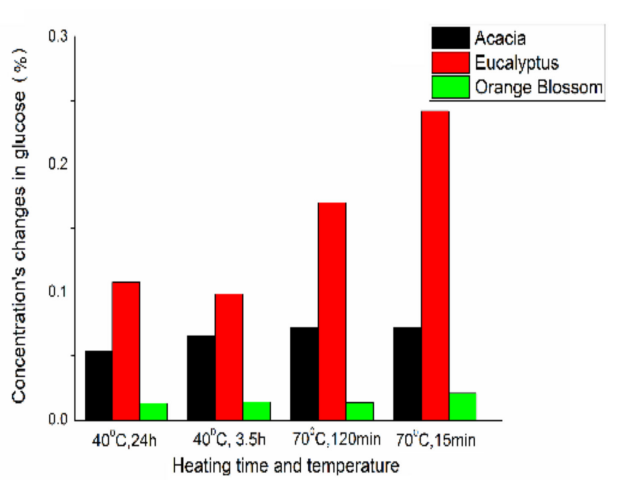

(b)

Figure 5. Relative changes in fructose (a) and glucose (b) concentrations, due to heating at different time and temperatures based on chromatography data (Table S2).

It turns out that a special strength of our model is its ability to determine even small mutual transformations in sugar composition that occur during heating. Such transformations could also be revealed by chromatography; however, this technique requires much more complex sample preparation and takes much more time than chemometric analysis. The complete results with data for accuracy and precision for acacia and orange blossom honey are given in the Supplementary Materials in Table S3. These results clearly indicate that the model works independently of honey type and composition.

\section{Conclusions}

The combination of Fourier-transform infrared spectroscopy with chemometric methods proves a powerful technique for quick and high accurate evaluation of the quality of honey. For FTIR analysis, no specific sample preparation is required. For three different types of honey, it has been shown that by the combination of said methods, thermal treatment of honey can be reliably detected. Heating of honey can generally have two origins, first, it can happen during transportation or storage, and, second, by intended heating regardless of the purpose. Principal component analysis (PCA) demonstrates the capability of differentiating between thermally treated and raw honey. Beyond that, by linear discriminant analysis (LDA) we can also quantitatively discriminate different conditions of thermal treatment.

In summary, FTIR spectroscopy complemented by chemometric methods allows for a quick and easy control of the quality of honey and can give a precise indication of unfavorable transport or storage conditions, or adulteration in case of incorrectly labeled raw honey.

Supplementary Materials: The data presented in this study are available within the manuscript and the Supplementary Materials. The following are available online at https:/ / www.mdpi.com/article/ 10.3390/foods10112892/s1, Figure S1: Principal component score plot of raw and thermally treated eucalyptus honey samples-15, 30, 60, 90 and $120 \mathrm{~min}$ at $70^{\circ} \mathrm{C}$-based on PCA applied to the spectral range of $800-1500 \mathrm{~cm}-1$ from FTIR data, Figure S2: Principal component score plot of raw and thermally treated eucalyptus honey samples-3.5, 5.5, 7.5 and $24 \mathrm{~h}$ at $40{ }^{\circ} \mathrm{C}$-based on PCA applied to the spectral range of $800-1500 \mathrm{~cm}-1$ from FTIR data, Figure S3: PCA score and loading plots of different raw and thermally treated eucalyptus honey samples-3.5 and $24 \mathrm{~h}$ at $40{ }^{\circ} \mathrm{C}$-analyzed in the spectral range of $800-1500 \mathrm{~cm}-1$. Figure S4: Ratio of intensities of fructose and glucose bands 
(990 and $1050 \mathrm{~cm}-1$ ) based on FTIR spectra at $40{ }^{\circ} \mathrm{C}$ and $70{ }^{\circ} \mathrm{C}$ for eucalyptus honey, Table S1: HMF content in honey after heat treatment, measured by chromatography, Table S2: Fructose, glucose, and sucrose concentrations in different types of honey, measured by chromatography, Table S3: Accuracy and precision of honey classification after heat treatment.

Author Contributions: Conceptualization, O.A. and A.S.; methodology, O.A. and A.S.; software, O.A. and J.C.; validation, O.A. and J.C.; formal analysis, O.A. and A.S.; investigation, O.A. and J.C.; resources, A.S. and J.C.; data curation, O.A. and J.C.; writing-original draft preparation O.A.; writing-review and editing A.S and J.C.; visualization, O.A.; supervision A.S.; project administration, A.S.; funding acquisition, A.S. and J.C.; All authors have read and agreed to the published version of the manuscript.

Funding: This work was supported by the Spanish Ministry of Economy, Industry and Competitiveness under the Maria de Maeztu Units of Excellence Programme - MDM-2016-0618 and MDM-20170720; further financial support was awarded by the Basque Government in the Elkartek Program $2019 / 20$.

Institutional Review Board Statement: Not applicable.

Informed Consent Statement: Not applicable.

Data Availability Statement: The data presented in this study are available within the manuscript and the Supplementary Materials (Figures S1-S4, and Tables S1-S3).

Conflicts of Interest: The authors declare no conflict of interest.

\section{References}

1. Belitz, H.-D.; Grosch, W.; Schieberle, P. Food Chemistry; 4th revise; Springer: Berlin, Germany, 2009; ISBN ISBN 9783540699330.

2. Khan, I.U.; Dubey, W.; Gupta, V. Medicinal Properties of Honey: A Review. Int. J. Pure App. Biosci. 2014, 2, 149-156.

3. Lu, J.; Cokcetin, N.N.; Burke, C.M.; Turnbull, L.; Liu, M.; Carter, D.A.; Whitchurch, C.B.; Harry, E.J. Honey can inhibit and eliminate biofilms produced by Pseudomonas aeruginosa. Sci. Rep. 2019, 9, 1-13. [CrossRef] [PubMed]

4. Eteraf-Oskouei, T.; Najafi, M. Traditional and modern uses of natural honey in human diseases: A review. Iran. J. Basic Med. Sci. 2013, 16, 731-742. [CrossRef] [PubMed]

5. Blasa, M.; Candiracci, M.; Accorsi, A.; Piacentini, M.P.; Albertini, M.C.; Piatti, E. Raw Millefiori honey is packed full of antioxidants. Food Chem. 2006, 97, 217-222. [CrossRef]

6. Mandal, M.D.; Mandal, S. Honey: Its medicinal property and antibacterial activity. Asian Pac. J. Trop. Biomed. 2011, 1, 154-160. [CrossRef]

7. Eshete, Y.; Eshete, T. A Review on the Effect of Processing Temperature and Time duration on Commercial Honey Quality. Madridge J. Food Technol. 2019, 4, 158-162. [CrossRef]

8. Subramanian, R.; Hebbar, H.U.; Rastogi, N.K. Processing of honey: A review. Int. J. Food Prop. 2007, 10, 127-143. [CrossRef]

9. Elamine, Y.; Anjos, O.; Estevinho, L.M.; Lyoussi, B.; Aazza, S.; Miguel, M.G. Effect of extreme heat processing on the Moroccan Zantaz' honey antioxidant activities. J. Food Sci. Technol. 2020, 57, 3323-3333. [CrossRef]

10. Quevedo, P.B.; Pensado, M.Á.B.; Romero, R.J.; Martínez, A.R. Optical Determination of the Effects by Thermal Treatment (TT) in Honey of Apis mellifera Bees. J. Agric. Chem. Environ. 2020, 9, 37-47. [CrossRef]

11. Skaff, W.; El Hajj, R.; Hanna-Wakim, L.; Estephan, N. Detection of adulteration in honey by infrared spectroscopy and chemometrics: Effect on human health. J. Food Process. Preserv. 2021, 10, e15438. [CrossRef]

12. Singh, I.; Singh, S. Honey moisture reduction and its quality. J. Food Sci. Technol. 2018, 55, 3861-3871. [CrossRef]

13. Shapla, U.M.; Solayman, M.; Alam, N.; Khalil, M.I.; Gan, S.H. 5-Hydroxymethylfurfural (HMF) levels in honey and other food products: Effects on bees and human health. Chem. Cent. J. 2018, 12, 1-18. [CrossRef]

14. Ajlouni, S.; Sujirapinyokul, P. Hydroxymethylfurfuraldehyde and amylase contents in Australian honey. Food Chem. 2010, 119, 1000-1005. [CrossRef]

15. Tosi, E.A.; Ré, E.; Lucero, H.; Bulacio, L. Effect of honey high-temperature short-time heating on parameters related to quality, crystallisation phenomena and fungal inhibition. LWT-Food Sci. Technol. 2004, 37, 669-678. [CrossRef]

16. Blidi, S.; Panagiota, G.; Sofia, L.; Spyros, G.; Antony, C.C. Effect of Thermal Treatment on the Quality of Honey Samples from Crete. Adv. Food Sci. Eng. 2017, 1, 1-8. [CrossRef]

17. Sereia, M.J.; Março, P.H.; Perdoncini, M.R.G.; Parpinelli, R.S.; de Lima, E.G.; Anjo, F.A. Techniques for the Evaluation of Physicochemical Quality and Bioactive Compounds in Honey. In Honey Analysis; IntechOpen: London, UK, 2017.

18. Bogdanov, S. (PDF) Honey Technology. In The Book of Honey; Bee Product Science: Muehlethurnen, Switzerland, 2010.

19. Sircar, A. Kriti Yadav Application of Geothermal Water for Honey Processing. In Proceedings of the Application of Geothermal Water for Honey Processing, Palo Alto, CA, USA, 12-14 February 2018.

20. Turhan, I.; Tetik, N.; Karhan, M.; Gurel, F.; Reyhan Tavukcuoglu, H. Quality of honeys influenced by thermal treatment. LWT-Food Sci. Technol. 2008, 41, 1396-1399. [CrossRef] 
21. Oliphant, T.E. Guide to NumPy; CreateSpace Independent Publishing Platform: Scotts Valley, CA, USA, 2006; Volume 1, ISBN 978-1-5173-0007-4.

22. Pedregosa, F.; Varoquaux, G.; Gramfort, A.; Michel, V.; Thirion, B. Scikit-learn: Machine Learning in Python. J. Mach. Learn. Res. 2011, 12, 2825-2830.

23. Jollife, I.T.; Cadima, J. Principal component analysis: A review and recent developments. Philos. Trans. R. Soc. A Math. Phys. Eng. Sci. 2016, 374, 20150202. [CrossRef]

24. Kędzierska-Matysek, M.; Matwijczuk, A.; Florek, M.; Barłowska, J.; Wolanciuk, A.; Matwijczuk, A.; Chruściel, E.; Walkowiak, R.; Karcz, D.; Gładyszewska, B. Application of FTIR spectroscopy for analysis of the quality of honey. BIO Web Conf. 2018, 10, 2008. [CrossRef]

25. Kasprzyk, I.; Depciuch, J.; Grabek-Lejko, D.; Parlinska-Wojtan, M. FTIR-ATR spectroscopy of pollen and honey as a tool for unifloral honey authentication. The case study of rape honey. Food Control 2018, 84, 33-40. [CrossRef]

26. Stöbener, A.; Naefken, U.; Kleber, J.; Liese, A. Determination of trace amounts with ATR FTIR spectroscopy and chemometrics: 5-(hydroxymethyl)furfural in honey. Talanta 2019, 204, 1-5. [CrossRef]

27. Rios-Corripio, M.A.; Rojas-López, M.; Delgado-Macuil, R. Analysis of adulteration in honey with standard sugar solutions and syrups using attenuated total reflectance-Fourier transform infrared spectroscopy and multivariate methods. CYTA-J. Food 2012, 10, 119-122. [CrossRef]

28. Wiercigroch, E.; Szafraniec, E.; Czamara, K.; Pacia, M.Z.; Majzner, K.; Kochan, K.; Kaczor, A.; Baranska, M.; Malek, K. Raman and infrared spectroscopy of carbohydrates: A review. Spectrochim. Acta Part A Mol. Biomol. Spectrosc. 2017, 185, 317-335. [CrossRef] 